\title{
$\mathrm{B}$-스프라인 곡선 모델링 및 메시-스펙트럼 변환을 이용한 프린트-스캔에 강인한 곡선 워터마킹
}

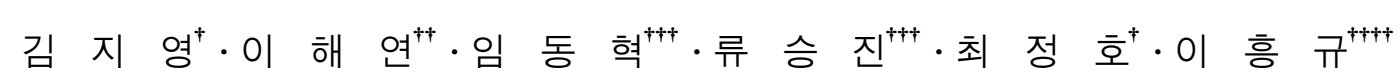

요 약

본 논문에서는 이미지의 선에 대하여 워터마크 정보를 삽입 및 추출하는 기술을 제안한다. 기존의 워터마킹 기술이 이미지의 픽셀 밝기값을 이용하는 것과 달리 제안된 알고리즘은 이미지의 곡선들을 $\mathrm{B}-$ 스프라인 곡선으로 모델화하여 $\mathrm{B}-$ 스프라인 제어점을 추출하고 이를 주파수 영역 으로 변환하여 워터마크를 삽입한다. 제어점에 Delaunay 삼각화를 적용하여 메시를 생성하고, 메시-스펙트럼 분석을 통하여 주파수 영역의 메 시-스펙트럼 계수를 계산한다. 워터마크는 이 계수의 중간 주파수 성분에 스프레드 스펙트럼 방식으로 삽입한다. 워터마크가 삽입된 계수를 메 시-스펙트럼 역변환을 통하여 제어점을 계산하고 이를 통하여 워터마크가 삽입된 $\mathrm{B}-$ 스프라인 곡선을 재구성할 수 있다. 삽입된 워터마크는 원 본 선 이미지를 사용하여 검출이 이루어진다. 먼저 대상 선 이미지를 $\mathrm{B}-$ 스프라인 모델화하고 곡선의 굴곡점을 이용하여 원본 선 이미지와 동 기화를 수행한다. 동기화된 이미지에서 워터마크 삽입과정과 같이 메시-스펙트럼 계수를 추출하고 원본 메시-스펙트럼 계수와의 차이값을 계산 하여 워터마크를 추출한다. 마지막으로 랜덤 워터마크와 추정된 워터마크의 상관 계수를 계산하여 삽입된 워터마크를 확인할 수 있다. 실험을 통하여 제안된 워터마킹 알고리즘이 기존 알고리즘보다 기하학적 공격과 프린트-스캔 공격에 강인함을 보였다.

키워드 : 강인한 워터마킹, B-스프라인 곡선, 메시-스펙트럼 변환, 프린트-스캔, 기하학적 공격

\section{Print-Scan Resilient Curve Watermarking using B-Spline Curve Model and its 2D Mesh-Spectral Transform}

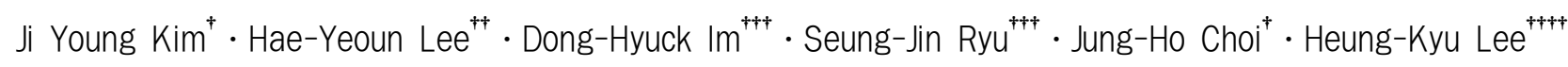

\begin{abstract}
This paper presents a new robust watermarking method for curves that uses informed-detection. To embed watermarks, the presented algorithm parameterizes a curve using the $\mathrm{B}$-spline model and acquires the control points of the $\mathrm{B}$-spline model. For these control points, 2D mesh are created by applying Delaunay triangulation and then the mesh spectral analysis is performed to calculate the mesh spectral coefficients where watermark messages are embedded in a spread spectrum way. The watermarked coefficients are inversely transformed to the coordinates of the control points and the watermarked curve is reconstructed by calculating B-spline model with the control points. To detect the embedded watermark, we apply curve matching algorithm using inflection points of curve. After curve registration, we calculate the difference between the original and watermarked mesh spectral coefficients with the same process for embedding. By calculating correlation coefficients between the detected and candidate watermark, we decide which watermark was embedded. The experimental results prove the proposed scheme is more robust than previous watermarking schemes against print-scan process as well as geometrical distortions.
\end{abstract}

Key Words : Robust watermarking, B-spline curve, mesh-spectral transform, print-scan, geometric attack

\section{1. 서 론}

\footnotetext{
※ This work was in part supported by the KOSEF grant NRL program funded by the Korea government (MOST) (No ROA-2007-000-20023-0), KOMSCO, and the IT R\&D program of MIC/ITTA (2007-S017-01, Development of user-centric contents protection and distribution technology) †준 회 원 : 한국과학기술원 전자전산학과 석사과정

†† 정 회 원: 국립금오공과대학교 컴퓨터공학부 교수(교신저자)

††† 준 회 원: 한국과학기술원 전자전산학과 박사과정

††+† 정 회 원 : 한국과학기술원 전자전산학과 교수 논문접수 : 2008 년 2월 14 일

심사완료 : 2008년 3월 25일
}

산업 발달이 가속화되면서 컴퓨터 및 고성능 스캐너와 프 린터 같은 전문 기기가 저가에 보급되고 있다. 이러한 디지 털 기기와 소프트웨어를 사용하여 불법 복제된 콘텐츠를 쉽 게 생산할 수 있다. 현재 영상 콘텐츠의 불법 복제를 대비 한 콘텐츠 보안 기술 중 하나로 디지털 워터마킹 기술이 연 구 및 실용화되어 있다. 디지털 워터마킹 기술은 원본 콘텐 츠에 저작권 정보를 비인지적으로 삽입하여 저작권 침해를 방지할 수 있는 기술이다. 지금까지 연구된 이미지 워터마 킹 방법은 이미지의 픽셀 밝기값을 미세하게 조정하여 워터 
마크를 삽입하였다. 그러나 네비게이션 시스템, GIS 디지털 지도, 만화의 경우 이미지를 직선과 곡선으로 표현하는데 이는 기존 이미지의 표현법과는 다른 방법으로 기존의 워터 마킹 기술을 적용하기에 어려움이 있다. 따라서 이에 적합 한 워터마킹 기술이 필요하다.

Solachidis과 Pitas[1]은 선 이미지에 대하여 푸리에 기술 자의 크기 성분에 워터마크를 삽입하는 알고리즘을 제안하 였는데 이는 기하학적인 공격에 강인한 성질을 나타내었다. 이외에도 $\mathrm{Gou}$ 와 $\mathrm{Wu}[2]$ 와 Ohbuchi et al.[3]은 각각 $\mathrm{B}-$ 스프 라인 곡선 모델을 이용한 워터마킹 기법과 메시-스펙트럼 계수를 활용한 워터마킹 방법에 대해 제안하였다. 제 2 장 에서는 이들 기법에서 사용한 방법과 문제점에 대하여 알아 보도록 하겠다.

본 논문에서 제안하는 워터마킹 알고리즘은 입력되는 선 을 $\mathrm{B}$-스프라인 모델로 모델링한 제어점에 대해 Delaunay 삼각화 및 메시-스펙트럼 변환을 하여 주파수 계수를 구한 후 스프레드 스펙트럼 방식으로 워터마크를 삽입한다. 워터 마크가 삽입된 주파수 계수는 메시-스펙트럼 역변환, $\mathrm{B}-$ 스 프라인 모델을 통하여 워터마크가 삽입된 선 이미지로 재구 성된다. 워터마크 추출 과정에서는 워터마크가 삽입된 선 이미지에서 삽입 과정과 동일한 과정으로 메시-스펙트럼 계 수를 구하고, 이를 원본 계수와 비교하여 워터마크를 추출 하게 된다. 상관 계수를 이용한 검증 단계를 거쳐 삽입된 워터마크를 확인할 수 있다. 제안한 알고리즘은 $\mathrm{B}$-스프라인 제어점의 지역 근사성의 장점을 유지한다. $\mathrm{B}^{-}$스프라인은 다 른 곡선 모델과 달리 특정 제어점의 변화가 지역적으로만 영향력을 가질 뿐 곡선 전 영역의 형태에 영향을 미치지 않 고 부드러운 곡선을 재구성하는데 탁월하다. 선 데이터 9 종 에 대하여 성능분석을 수행한 결과 제안하는 알고리즘의 성 능이 기하학적 공격과 프린트-스캔 공격에 대하여 기존 알 고리즘들에 비해 우수하다는 것을 알 수 있다.

논문의 구성은 다음과 같다. 제 2 장에서 관련 연구에 대하 여 설명하고, 제 3 장에서 제안하는 알고리즘의 워터마크 생 성과 삽입 및 추출 과정을 설명한다. 제4장에서 다양한 기 하학적 공격과 프린트-스캔 공격에 대한 제안한 알고리즘의 성능을 비교 분석하였다. 마지막으로 제 5 장에서 결론과 향 후 연구에 대해 기술하겠다.

\section{2. 관련 연구}

\section{$2.1 \mathrm{~B}-$ 스프라인 곡선의 제어점을 이용한 워터마킹}

$\mathrm{Gou}$ 와 $\mathrm{Wu}$ 은 $\mathrm{B}$-스프라인 곡선 모델을 이용하여 지도상 의 선 이미지에 대하여 제어점을 추출하고, 이에 워터마크 를 삽입하는 연구를 하였다[2]. 제어점은 곡선의 형태를 제 어하는 곡선 외부의 점들을 말한다. 제어점을 구하기 위해 다음과 같이 곡선 상의 점들의 집합 $\mathrm{P}$ 를 $\mathrm{B}-$ 스프라인 모델 로 표현한다[4].

$$
p^{[B]}(t)=\sum_{i=0}^{n-1} c_{i} B i, k(t)
$$

이때 $\mathrm{c}$ 는 제어점, $\mathrm{n}$ 은 제어점의 수이고, $\mathrm{t}=0,1,2 \ldots, \mathrm{n}$ 이다. $\mathrm{B}$ 는 가중치 함수이고, $\mathrm{k}$ 는 가중치 함수의 차수이다. 위의 식을 이용하여 원본 곡선 $\mathrm{P}$ 와 $\mathrm{B}^{-}$스프라인으로 모델화된 $P^{[B]}$ 의 차이를 최소화하는 $\mathrm{n}$ 개의 제어점을 구할 수 있다. 마 지막으로 노이즈 형태의 워터마크를 생성하여 제어점 좌표 에 스프레드 스펙트럼 형태로 삽입하고 상관 계수 기반 검 출 방법을 통하여 삽입된 워터마크를 확인한다.

(그림 1 )는 $\mathrm{B}$-스프라인 곡선의 제어점을 이용한 워터마 킹 기법을 설명한다. (그림 1-ㄱ)에 원본 곡선과 이 곡선에 서 추출한 제어점을 원으로 표시하였다. (그림 1)에서 보듯 이 곡선의 제어점이 곡선 형태를 제어하고 있음을 볼 수 있 다. 본 제어점에 워터마크를 삽입하여 좌표값을 변경하면 (그림 1-ㄴ)과 같이 곡선의 모양이 변화한다. 그러나 곡선의 왜곡을 인지하기 어려운 부드러운 곡선을 만들 수 있다.

본 방법은 하나의 곡선을 표현하는 제어점이 유일하지 않 기 때문에 검출 과정에서 원본 제어점와 유사한 포인트를 찾아야 하는 문제가 있다. 따라서 우수한 동기화 알고리즘 과 반복적인 연산 과정이 필요하다. 또한 본 논문의 실험 결과에서 보듯이 단순히 제어점의 좌표에 워터마크를 삽입 한 경우 프린트-스캔 공격에서 상대적으로 워터마크 검출율 이 낮고, 재구성된 이미지의 훼손 정도도 크다.

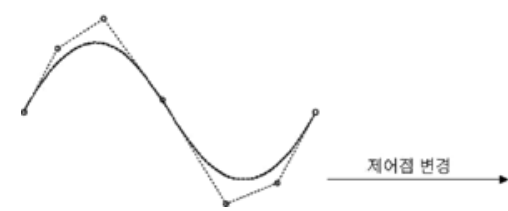

( ᄀ)

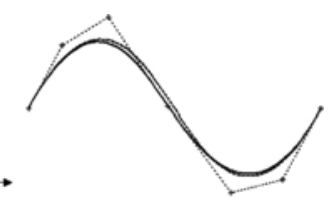

( ᄂ )
(그림 1) B-스프라인 곡선의 제어점 예: ( ᄀ ㄱ) 원본 곡선과 그의 제어점 및 ( ㄴ) 원본 곡선, 변경된 제어점과 재구성된 곡선

\section{$2.22 \mathrm{D}$ 메시-스펙트럼 변환을 이용한 워터마킹}

벡터 지도는 정점과 선으로 표현된다. Ohbuchi et al. 는 정점으로 생성한 메시를 이용하여 워터마크를 삽입하는 방 법을 제시하였다[3]. 먼저 정점에 대하여 Delaunay 삼각화를 통하여 생성한 메시로 부터 $\mathrm{nxn}$ 라플라시안 행렬을 다음과 같이 계산한다.

$$
R=I-H A
$$

이렇게 생성된 $\mathrm{R}$ 을 eigen 분석을 하면 $\mathrm{n}$ 개의 eigen 벡터 와 eigen 값을 구할 수 있다. $n$ 개의 점을 eigen 벡터에 투사 하면 $\mathrm{n}$ 개의 메시-스펙트럼 계수를 구할 수 있다. 이렇게 지 도를 주파수 영역으로 표현한 후, 추출한 계수에 $\{+1,-1\}$ 의 랜덤한 워터마크를 스프레드 스펙트럼 형태로 삽입하고 역 변환을 통해서 지도를 재구성한다. 워터마크 검출시에는 주 파수 영역의 계수와 워터마크의 상관계수를 계산하여 삽입 된 워터마크를 확인한다.

본 메시-스펙트럼을 이용한 기법에 대해 실험을 통하여 분석해본 결과 기하학적 공격에 강인한 성능을 보였다. 그 
러나 본 기법은 지도의 빌딩, 집, 도로 등 다각형의 도형에 대해 적용되었고 곡선에 대해 적용된 모델이 아니다. 또한 모든 정점으로 메시를 계산하는 것이 복잡도가 크다는 한계 를 가지고 있다.

\section{3. 제안하는 강인한 선기반 워터마킹 알고리즘}

본 논문에서는 선 이미지에 대하여 강인한 워터마킹 알고 리즘을 제안하였다. 제안된 알고리즘의 워터마크 삽입 및 검출 과정은 (그림 2)에 도시하였다. 선 이미지에 대하여 전 처리를 수행한 후에 $\mathrm{B}-$ 스프라인 곡선 모델링을 통하여 제 어점을 추출하고, 이에 대하여 Delaunay 삼각화 및 메시-스 펙트럼 분석을 적용한 후에 생성된 주파수 계수에 워터마크 를 삽입하였다. 워터마크 삽입된 계수에 대하여 역변환을 통하여 제어점을 계산하고 곡선을 구성함으로써 워터마크가 삽입된 선을 재구성할 수 있다. 워터마크 검출은 삽입과 유 사한 과정을 통하여 이루어진다. 다만 기하학적인 비동기화 문제는 선동기화의 과정을 통하여 해결하였다. 또한 원본 선 이미지를 사용한 상관도 계산을 통하여 삽입된 워터마크 를 확인하였다. 각 과정에 대하여 다음 세부 절에서 구체적 으로 설명하도록 하겠다.

제안한 알고리즘은 $\mathrm{B}-$ 스프라인 곡선의 지역 근사성을 장 점으로 유지한다. 베지어 곡선과 같은 다른 곡선 모델은 제 어점의 위치가 변화하면 곡선 전체의 모양이 변화하지만 $\mathrm{B}$-스프라인 곡선은 해당 부분만 곡선 모양이 변한다. 또한 제어점의 미세한 변경은 곡선의 왜곡이 거의 없기 때문에 사람의 눈으로 그 차이를 쉽게 알 수 없다. 본 논문에서 제 어점들을 추가적으로 주파수 영역으로 변환하여 워터마크를

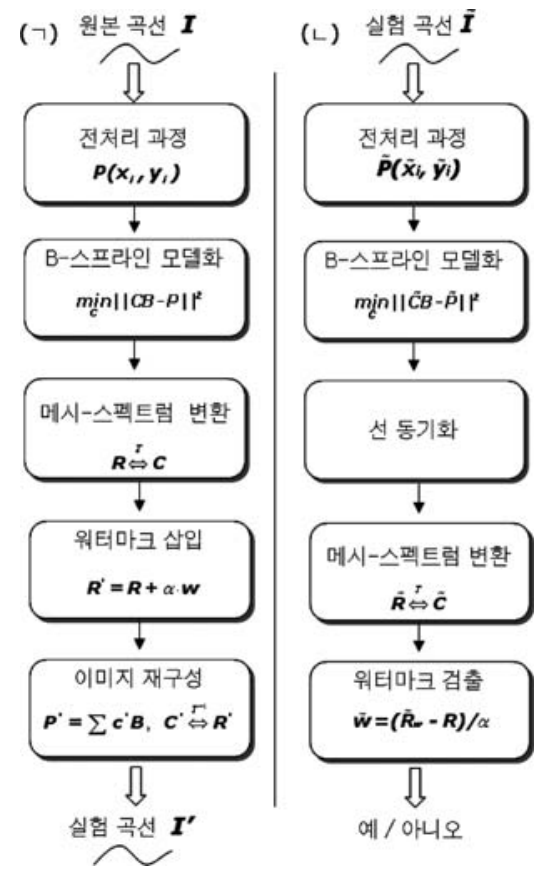

(그림 2) 제안하는 선기반 워터마킹 알고리즘 개요: (ㄱ)워터마 크 삽입 및 ( $\llcorner$ )검출 과정
삽입하기 때문에 기하학적 공격에 강인하고 분석 결과 프린 트-스캔에 강인함을 보였다.

\section{1 전처리 과정}

전처리 과정에서는 $\mathrm{B}$-스프라인 곡선 모델화를 위하여 원 본 선 이미지를 1-픽셀 두께의 선으로 변환하였다. 이를 위 해 이진화 및 세선화의 과정을 수행하였다. 대부분의 경우 프린트-스캔 등을 통한 영상은 이진 영상이 아니기 때문에 각 픽셀 밝기값이 0 에서 255 사이에 분포한다. 정제된 곡 선을 추출하기 위해 임계값 200으로 곡선을 이진화한다. 이 렇게 변환된 이진 영상에서 이상적인 곡선을 추출하기 위해 다양한 픽셀 넓이의 선을 1 -픽셀 두께의 선으로 표현하기 위하여 세선화 기법을 적용하였다.

\section{$3.2 \mathrm{~B}-$ 스프라인 모델링 및 제어점 추출}

전처리된 영상에서 1-픽셀 곡선의 형태를 추정하기 위해 서 곡선의 각 점에 인덱스를 부여한다. 시작점과 끝점을 추 정하고 한 점의 8 방향으로 우선 순위를 정하여 곡선을 따 라간다. 왜곡으로 인한 곡선의 끓김 현상이 일어나는 경우 나 곡선 가운데 폐곡선이 만들어진 경우 등에 대해 보정을 하여 단일곡선을 생성한다. 아래 <표 $1>$ 은 곡선 추정시 방 향의 우선 순위를 나타낸다.

곡선의 좌표 값을 순차적으로 얻은 이후 균일하게 샘플링 하여 샘플 포인트를 추출하고 이를 이용하여 $\mathrm{B}$-스프라인 곡선 모델화에 사용한다. 본 논문에서 사용한 샘플링 간격 은 6 이다. 샘플 포인트는 다음과 같이 $\mathrm{B}$-스프라인 곡선으 로 될 수 있다[4].

$$
p^{[B]}(t)=\sum_{i=0}^{n-1} c_{i} B i, k(t)
$$

이때 $\mathrm{c}$ 는 제어점, $\mathrm{n}$ 은 제어점의 수이고, $\mathrm{t}=0,1,2 \cdots, \mathrm{n}$ 이다. 가중치 함수 $\mathrm{B}$ 는 다음과 같이 정의된다.

$$
\begin{aligned}
& B_{i, 1}(t)= \begin{cases}1, & t_{i} \leq t<t_{i}+1 \\
0, & \text { otherwise }\end{cases} \\
& B_{i, k}(t)=\frac{\left(t-t_{i}\right) B_{i, k-1}(t)}{t_{i+k-1}-t_{i}}+\frac{\left(t_{i+k}-t\right) B_{i+1, k-1}(t)}{t_{i+k}-t_{i+1}} \\
& k=2,3, \ldots
\end{aligned}
$$

〈표 1〉 곡선 추정 우선 순위 정의

\begin{tabular}{|c|c|c|c|c|c|c|c|c|c|c|}
\hline \multirow{2}{*}{ 이전 방향성 } & \multicolumn{10}{|c|}{ 방향 추정 우선 순위 } \\
\cline { 2 - 12 } & 1 & 2 & 3 & 4 & 5 & 6 & 7 & 8 & 9 & 10 \\
\hline \hline $\mathrm{E}->\mathrm{W}$ & - & - & $\mathrm{W}$ & $\mathrm{SW}$ & $\mathrm{S}$ & $\mathrm{SE}$ & $\mathrm{E}$ & $\mathrm{NE}$ & $\mathrm{N}$ & $\mathrm{NW}$ \\
\hline $\mathrm{NE}->\mathrm{SW}$ & $\mathrm{SW}$ & $\mathrm{W}$ & $\mathrm{SW}$ & $\mathrm{S}$ & $\mathrm{SE}$ & $\mathrm{E}$ & $\mathrm{NE}$ & $\mathrm{N}$ & $\mathrm{NW}$ & $\mathrm{W}$ \\
\hline $\mathrm{N}->\mathrm{S}$ & - & - & $\mathrm{S}$ & $\mathrm{SE}$ & $\mathrm{E}$ & $\mathrm{NE}$ & $\mathrm{N}$ & $\mathrm{NW}$ & $\mathrm{W}$ & $\mathrm{SW}$ \\
\hline $\mathrm{NW}->\mathrm{SE}$ & $\mathrm{SE}$ & $\mathrm{S}$ & $\mathrm{SE}$ & $\mathrm{E}$ & $\mathrm{NE}$ & $\mathrm{N}$ & $\mathrm{NW}$ & $\mathrm{W}$ & $\mathrm{SW}$ & $\mathrm{S}$ \\
\hline $\mathrm{W}->\mathrm{E}$ & - & - & $\mathrm{E}$ & $\mathrm{NE}$ & $\mathrm{N}$ & $\mathrm{NW}$ & $\mathrm{W}$ & $\mathrm{SW}$ & $\mathrm{W}$ & $\mathrm{SE}$ \\
\hline $\mathrm{SW}->\mathrm{NE}$ & $\mathrm{NE}$ & $\mathrm{E}$ & $\mathrm{NE}$ & $\mathrm{N}$ & $\mathrm{NW}$ & $\mathrm{W}$ & $\mathrm{SW}$ & $\mathrm{W}$ & $\mathrm{SE}$ & $\mathrm{E}$ \\
\hline $\mathrm{S}->\mathrm{N}$ & - & - & $\mathrm{N}$ & $\mathrm{NW}$ & $\mathrm{W}$ & $\mathrm{SW}$ & $\mathrm{S}$ & $\mathrm{SE}$ & $\mathrm{E}$ & $\mathrm{NE}$ \\
\hline $\mathrm{SE}->\mathrm{NW}$ & $\mathrm{NW}$ & $\mathrm{N}$ & $\mathrm{NW}$ & $\mathrm{W}$ & $\mathrm{SW}$ & $\mathrm{S}$ & $\mathrm{SE}$ & $\mathrm{E}$ & $\mathrm{NE}$ & $\mathrm{N}$ \\
\hline
\end{tabular}


여기서 $\mathrm{t}_{\mathrm{i}}$ 는 knots 라고 불리고 $\mathrm{B}$-스프라인 함수가 함께 연결되는 위치를 의미하는 것으로 $\mathrm{B}-$ 스프라인 함수와 제어 점을 제어하게 된다. $\mathrm{k}$ 는 가중치 함수의 차수를 의미하고 본 논문에서는 4 차를 적용하여 cubic B-스프라인 함수를 이 용하였다. 위의 두 식을 이용하여 원본 곡선과 가장 유사한 $\mathrm{B}$-스프라인 곡선을 생성한다. 위의 식으로부터 제어점을 추출 하기 위해서 다음과 같이 샘플 포인트와 제어점을 정의한다.

$$
P=\left[\begin{array}{cc}
x_{0} & \mathrm{y}_{0} \\
x_{1} & \mathrm{y}_{1} \\
\ldots & \ldots \\
x_{m-1} & \mathrm{y}_{\mathrm{m}-1}
\end{array}\right], \quad C=\left[\begin{array}{cc}
c_{x_{0}} & c_{y_{0}} \\
c_{x 1} & c_{y_{1}} \\
\ldots & \ldots \\
c_{x_{n-1}} & c_{y_{n-1}}
\end{array}\right]
$$

그리고 최소자승법을 이용하여 정확한 제어점 $\mathrm{C}$ 를 다음 과 같이 구할 수 있다.

$$
\min _{C}\|C B-P\|^{2} \rightarrow C=B^{\dagger} P
$$

\section{3 메시-스펙트럼 변환}

$\mathrm{B}-$ 스프라인 곡선의 제어점들을 주파수 영역으로 변환하 기 위하여 Delaunay 삼각화를 통하여 생성한 메시로 부터 $\mathrm{nxn}$ 라플라시안 행렬을 다음과 같이 계산한다.

$$
R=I-H A
$$

I는 단위 행렬이고, $\mathrm{H}$ 는 대각 성분이 $1 / \mathrm{d}_{\mathrm{i}}$ 인 대각 행렬이 고, $\mathrm{d}_{\mathrm{i}}$ 는 $\mathrm{i}$ 번째 점에서의 교선의 수이며, $\mathrm{A}$ 는 인접 행렬이 다. 만약 $i$ 번째 점과 $j$ 번째 점이 인접해 있다면 $\mathrm{A}$ 의 $\mathrm{i}$ 행, $\mathrm{j}$ 열 에 해당하는 원소는 1 의 값을 가진다. 그 외의 경우는 0 으 로 값을 할당한다. 이렇게 생성된 $\mathrm{R}$ 을 eigen 분석을 하면 $\mathrm{n}$ 개의 eigen 벡터와 eigen 값을 구할 수 있다. $\mathrm{n}$ 개의 제어점 을 eigen 벡터에 투사하면 $\mathrm{n}$ 개의 메시-스펙트럼 계수 벡터 $\mathrm{r}_{\mathrm{i}}(1 \leq \mathrm{i} \leq \mathrm{n})=\left(\mathrm{r}_{\mathrm{s}, \mathrm{i}}, \mathrm{r}_{\mathrm{t}, \mathrm{i}}\right)$ 를 구할 수 있다. 계수의 첨자 $\mathrm{s}$ 와 $\mathrm{t}$ 는 $\mathrm{x}, \mathrm{y}$ 축과 대칭된 직교 좌표계를 말한다. 이렇게 생성된 메시는 기본적으로 기하학적 공격에 강인한 특성을 가진다.

\section{4 워터마크 삽입}

제안한 알고리즘은 상기의 과정을 통하여 계산된 메시스펙트럼 계수에 대하여 스프레드 스펙트럼 방식으로 이 계 수 값을 변경시킴으로써 워터마크가 삽입한다. 삽입을 위한 워터마크는 평균이 0 인 정규분포를 따르고, 1 과 -1 로 이루 어진 길이 $\mathrm{L}$ 의 랜덤 시퀀스로 생성한다. 이렇게 생성된 워 터마크 $\mathrm{W}$ 는 아래 식과 같이 chip rate $c r$ 만큼 스프레드하여 워터마크 $\mathrm{b}$ 를 생성한다.

$$
b_{i}=w_{j} / c r, \quad j \cdot c r \leq i \leq(j+1) \cdot c r
$$

생성된 워터마크 $\mathrm{b}$ 의 길이는 $\mathrm{cr} \cdot \mathrm{L}$ 이다. 워터마크 $\mathrm{b}$ 는 스 프레드 스펙트럼 계수 $\mathrm{r}$ 에 다음과 같이 세기 $\mathrm{a}$ 로 삽입되어 워터마크가 삽입된 메시-스펙트럼 계수 $\mathrm{r}^{\prime}$ 를 생성한다.

$$
r^{\prime}{ }_{i}=r_{i}+b_{i} \cdot \alpha
$$

Sonlanki et al.[5]의 연구에 의하면, 프린트-스캔 과정에 의해 발생하는 컬러 노이즈나 비선형 효과 등은 이미지의 고주파 계수를 변화시키기 때문에 프린트-스캔 과정에도 살 아남는 워터마크 삽입 방법은 저주파나 중간주파 영역의 계 수에 워터마크를 삽입하는 것이다. 그 중 저주파 영역의 계 수의 변화는 원본 선에 더 왜곡을 일으키므로, 본 논문에서 는 중간 주파수 영역의 메시-스펙트럼 계수에 워터마크를 삽입하도록 하였다.

\section{5 이미지 재구성}

워터마크가 삽입된 메시-스펙트럼 계수를 메시-스펙트럼 역변환하면 워터마크가 삽입된 제어점을 추출할 수 있다. 이를 위하여 워터마크가 삽입된 메시-스펙트럼 계수 $r^{\prime}{ }_{i}=$ $\left(\mathrm{r}_{\mathrm{s}, \mathrm{i}}^{\prime}, \mathrm{r}_{\mathrm{t}, \mathrm{i}}^{\prime}\right)$ 에서 제어점 $\mathrm{C}^{\prime}$ 를 다음 식을 통해서 계산할 수 있다. 여기서 $e_{i}$ 는 계수 $r_{i}$ 에 해당되는 정규 eigen 벡터이다.

$$
\begin{aligned}
& \left(c_{x_{1}}^{\prime}, c_{x_{2}}^{\prime}, \ldots, c_{x_{n}}^{\prime}\right)^{T}=r_{s, 1}^{\prime} e_{1}+r_{s, 2}^{\prime} e_{2}+\ldots+r_{s, 2}^{\prime} e_{n}, \\
& \left(c_{y_{1}}^{\prime}, c_{y_{2}}^{\prime}, \ldots, c_{y_{n}}^{\prime}\right)^{T}=r_{t, 1}^{\prime} e_{1}+r_{t, 2}^{\prime} e_{2}+\ldots+r_{t, 2}^{\prime} e_{n}
\end{aligned}
$$

위 식으로 구한 제어점이 워터마크가 삽입된 $\mathrm{B}-$ 스프라인 모델의 제어점이며 다음의 식을 이용하면 워터마크가 삽입 된 샘플 포인트를 얻을 수 있고 샘플 포인트를 보간하면 워 터마크가 삽입된 곡선을 추출할 수 있다.

$$
P^{\prime}(t)=\sum_{i=0}^{n-1} c_{i}^{\prime} B_{i, k}(t)
$$

\section{6 선 동기화}

워터마크의 검출을 위해서는 기하학적 공격뿐만 아니라 프린트-스캔 과정에 의한 미세한 곡선 위치 변화를 보정하 기 위하여 원본 선 이미지와 검출을 위한 대상 선 이미지를 동기화시켜야 한다. 두 곡선의 동기화 점은 Mokhtarian와 Mackworth[6]의 연구에서 착안하여 곡선의 굴곡점을 활용 하였다. 곡선의 굴곡점은 곡선의 모양을 바꾸지 않는 변환 과정에 강인하기 때문에 곡선 동기화를 수행할 수 있다. 동 기화 과정은 다음과 같다. 먼저 두 곡선의 굴곡점을 추출하 여 가장 유사한 굴곡점의 집합을 구한다. 원본 곡선의 굴곡 점을 $(\mathrm{x}, \mathrm{y})$ 라고 하고 대상 곡선의 굴곡점을 $(\tilde{x}, \tilde{y})$ 라고 하면 다음 식을 통하여 실험 곡선에 가해진 왜곡 변환을 계산할 수 있다.

$$
\left[\begin{array}{c}
\tilde{x} \\
\tilde{y}
\end{array}\right]=\left[\begin{array}{ll}
a_{11} & a_{12} \\
a_{21} & a_{22}
\end{array}\right]\left[\begin{array}{l}
x \\
y
\end{array}\right]+\left[\begin{array}{l}
a_{13} \\
a_{23}
\end{array}\right]
$$

위의 식을 좀 더 쉽게 표현하면 아래와 같이 왜곡 변환을 나타내는 단일 행렬 $\mathrm{A}$ 를 구할 수 있다.

$$
\left[\begin{array}{c}
\tilde{x} \\
\tilde{y} \\
1
\end{array}\right]=\left[\begin{array}{ccc}
a_{11} & a_{12} & a_{13} \\
a_{21} & a_{22} & a_{23} \\
0 & 0 & 1
\end{array}\right]\left[\begin{array}{l}
x \\
y \\
1
\end{array}\right]=A\left[\begin{array}{l}
x \\
y \\
1
\end{array}\right]
$$


따라서 대상 곡선의 모든 점 집합을 $(\tilde{X}, \tilde{Y})$ 라고 하고 원 본 곡선의 모든 점 집합을 $(\mathrm{X}, \mathrm{Y})$ 라고 할때 아래와 같이 왜 곡변환의 역변환을 취하면 대상 곡선 상의 모든 점을 원본 곡선 위치와 동기화할 수 있다.

$$
\left[\begin{array}{l}
X \\
Y \\
1
\end{array}\right]=A^{-1}\left[\begin{array}{l}
\tilde{X} \\
\tilde{Y} \\
1
\end{array}\right]
$$

(그림 3)은 원본 곡선과 프린트-스캔 과정을 거친 대상 곡선의 동기화 결과이다. 두 곡선에서 가장 적합한 굴곡점 집합을 정하여 왜곡 변환을 계산한다. 대상 곡선에 이 왜곡 의 역변환을 취하여 원본과 동기화를 하였다. 이러한 과정 은 원본 영상과 차이값이 가장 작을때까지 반복적으로 수행 된다. (그림 3)의 곡선에 대해서는 3 번의 반복 과정을 거쳤 다. (그림 4)의 왼쪽은 원본 곡선과 대상 곡선을 겹쳐 보이 고 오른쪽은 원본 곡선과 동기화된 대상 곡선을 겹쳐 보였 다. 이를 통해서 동기화된 곡선이 원본 곡선과 더 유사하다 는 것을 확인할 수 있다.
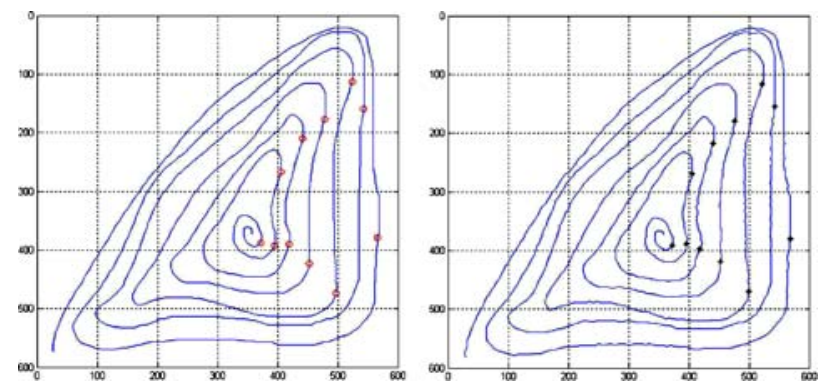

(그림 3) 곡선 동기화를 위한 원본 곡선(좌)과 프린트-스캔 대 상 곡선(우)의 상호 대칭되는 굴곡점 추출
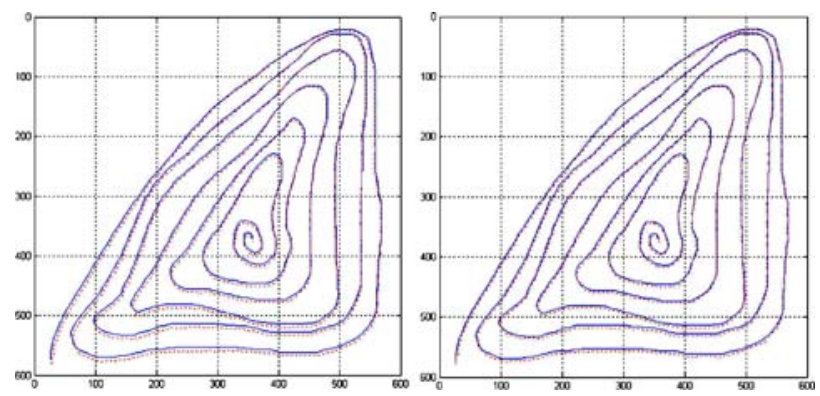

(그림 4) 원본과 프린트-스캔 곡선의 차이(좌) 와 원본과 동기 화된 곡선의 차이(우)

\section{7 워터마크 검출}

본 논문에서 제안한 알고리즘은 워터마크를 추출하기 위 해서 원본 곡선을 사용하는 non-blind 워터마킹 방식이다. 삽입된 워터마크를 추출 과정은 워터마크 삽입과 유사하게 처리된다. 먼저 곡선 동기화를 수행한 후에, 대상 곡선에서 원본 곡선의 샘플 포인트와 가장 유사한 샘플 포인트를 선 택하여 제어점 $\tilde{C}$ 를 추출한다. 추출한 제어점을 메시-스펙트
럼 분석을 하여 메시-스펙트럼 계수 $\tilde{r}$ 를 추출하고 원본 이 미지의 메시-스펙트럼 계수와의 차이를 다음 식으로 계산하 여 워터마크를 추출해 낼 수 있다.

$$
\tilde{b}_{i}=\left(\tilde{r}_{i}-r_{i}\right) / \alpha, \quad \tilde{w}_{j}=\sum_{i=j \cdot c r}^{(j+1) \cdot c r} \tilde{b}_{i}
$$

이렇게 추출한 워터마크와 삽입된 워터마크 간의 상관계 수를 계산하여 삽입된 워터마크를 확인한다. 본 논문에서는 강인한 워터마크의 검증에 적합한 $Z$ 통계치를 워터마크 검 증 방법으로 사용한다[7]. 다음 식과 같이 삽입된 워터마크 와 추출된 워터마크의 상관계수를 구한다. 이 때, $\mathrm{L}$ 은 워터 마크의 길이이며, $\mathrm{w}$ 는 삽입된 워터마크, $\tilde{w}$ 는 추출한 워터마 크를 의미한다. $\mu$ 는 삽입된 워터마크의 평균이고, $\tilde{\mu}$ 는 추출 한 워터마크의 평균이다.

$$
r=\frac{\sum_{i=1}^{L}\left(\tilde{w}_{i}-\tilde{\mu}\right)\left(w_{i}-\mu\right)}{\sqrt{\sum_{j=1}^{L}\left(\tilde{w}_{j}-\tilde{\mu}\right)^{2} \sum_{k=1}^{L}\left(w_{k}-\mu\right)^{2}}}
$$

상기의 식으로부터 다음과 같이 $Z$ 통계치를 구할 수 있다.

$$
Z=\frac{\sqrt{L-3}}{2} \log \frac{1+r}{1-r}
$$

\section{4. 실험 및 결과 분석}

본 절에서는 지도, 도형, 만화 캐릭터 등의 다양한 선 이 미지에 대한 실험을 통하여 제안된 알고리즘의 강인성을 보 인다. 실험은 <표 $2>$ 와 같이 총 9 개의 다른 선 이미지를 대 상으로 실시하였다. 참고로 (그림 5)는 실험에 사용한 9개의 선이미지 중 몇 개를 샘플로 나열한 것이다. 워터마크 삽입 세기는 0.5로 하고 Curve.tif를 제외한 모든 곡선 이미지에 길이 1000 비트의 워터마크를 삽입한다. Curve.tif 곡선에 대 해서는 560 비트의 워터마크를 삽입했다. 삽입된 워터마크 는 3.4 절에서 언급한 것과 같이 1 과 -1 로 이루어진 길이 1000 또는 560의 랜덤시퀀스로 생성한다.

〈표 2〉실험에 사용한 선 이미지 샘플

\begin{tabular}{|c|c|c|c|c|}
\hline 선 이미지 & 크기(픽셀) & 해상도 & 샘플 포인트 수 & 제어점 수 \\
\hline \hline Apple.tif & $756 \times 756$ & 96 & 675 & 686 \\
\hline Mountain.tif & $591 \times 591$ & 96 & 1118 & 1230 \\
\hline Car.tif & $629 \times 245$ & 96 & 578 & 599 \\
\hline Map.tif & $770 \times 708$ & 96 & 535 & 543 \\
\hline Leaf.tif & $756 \times 756$ & 96 & 919 & 976 \\
\hline Curve.tif & $634 \times 471$ & 96 & 273 & 280 \\
\hline Topo1.tif & $398 \times 251$ & 96 & 1188 & 1190 \\
\hline Topo2.tif & $459 \times 527$ & 96 & 2411 & 2418 \\
\hline Duck.tif & $634 \times 447$ & 96 & 1429 & 1432 \\
\hline
\end{tabular}




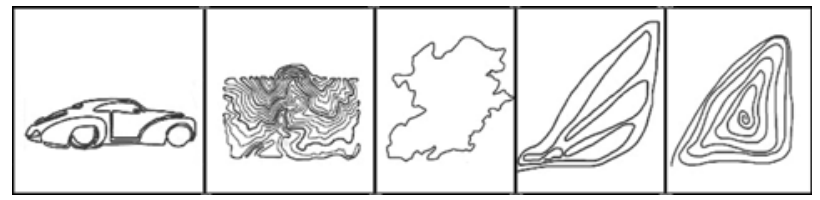

(그림 5) 실험에 사용한 선이미지 샘플

제안한 알고리즘의 성능을 분석하기 위하여 Gou와 $\mathrm{Wu}$ 가 제시한 제어점의 좌표값에 랜덤 노이즈 형태의 워터마 크를 삽입하는 선 워터마킹 알고리즘과 비교하였다[2]. 비교 를 위하여 두 곡선간의 거리 차이를 계산하여 곡선의 왜곡 정도를 나타내는 Hausdorff Distance $(\mathrm{HD})$ 와 워터마크 검출 율을 성능의 척도로 사용하였다. $d_{B}(A)$ 와 $d(a, B)$ 가 각각 $d_{B}(A)=\sup _{a \in A} d(a, B), d(a, B)=\inf _{b \in B} d(a, b)$ 로 정의될 때 $\mathrm{HD}$ 는 다음과 같이 계산된다[8]. 따라서, $\mathrm{HD}$ 는 서로 다른 두 곡선 간의 차이를 $\min -\max$ 메트릭을 이용하여 정량화 하는 방법이다.

$$
h(A, B)=d_{B}(A)+d_{A}(B)
$$

다음 (그림 6)은 Car.tif 선 이미지로부터 제어점을 추출 하여 주파수 영역으로 변환하고 워터마크를 삽입하여 워터 마킹 이미지를 재구성하는 과정을 보인다. 원본 이미지와 워터마크된 이미지를 사람의 눈으로 식별하기는 어렵다. 그 러나 원본 메시와 워터마킹 메시의 미세한 차이를 발견할 수 있다.
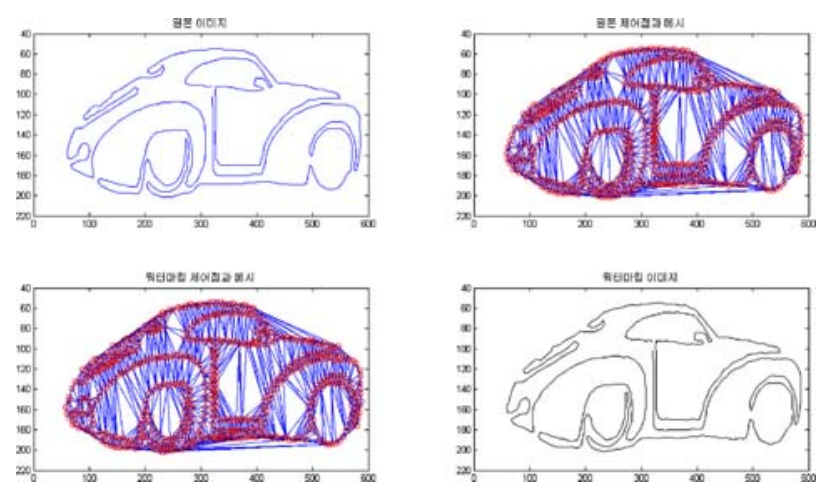

(그림 6) 제어점의 메시-스펙트럼 계수를 이용한 워터마킹 과정

\section{1 기하학적 공격에 대한 실험}

메시-스펙트럼 계수의 기하학적 공격에 대한 강인성을 분석하였다. 기하학적 공격에 대한 검출 결과의 정확성을 위하여 선은 이미지로 저장하지 않고 디지털 데이터를 사용 하고, 선 동기화 알고리즘도 적용하지 않았다. 선을 이미지 로 저장할 경우 절삭과정이 일어나서 데이터의 손실이 발생 하여 기하학적인 공격에 자체에 의한 영향을 확인할 수 없 다. (그림 7)은 기존의 제어점 좌표에 워터마크를 삽입한 경 우 기하학적 공격에 대한 워터마크 검출 결과이다. 1000 개 의 랜덤 워터마크 중 500 번째의 워터마크를 삽입하였는데 Gou와 $\mathrm{Wu}$ 알고리즘의 경우 회전 공격과 확대 공격, 이동 공격에서 모두 워터마크를 추출하지 못하였다. 제안한 알고
리즘에 대한 결과는 (그림 8)에 나타나 있다. 주파수 영역으 로 변환한 경우 선 동기화 알고리즘을 적용하지 않아도 기 하학적 공격에서 강인함을 보였다.
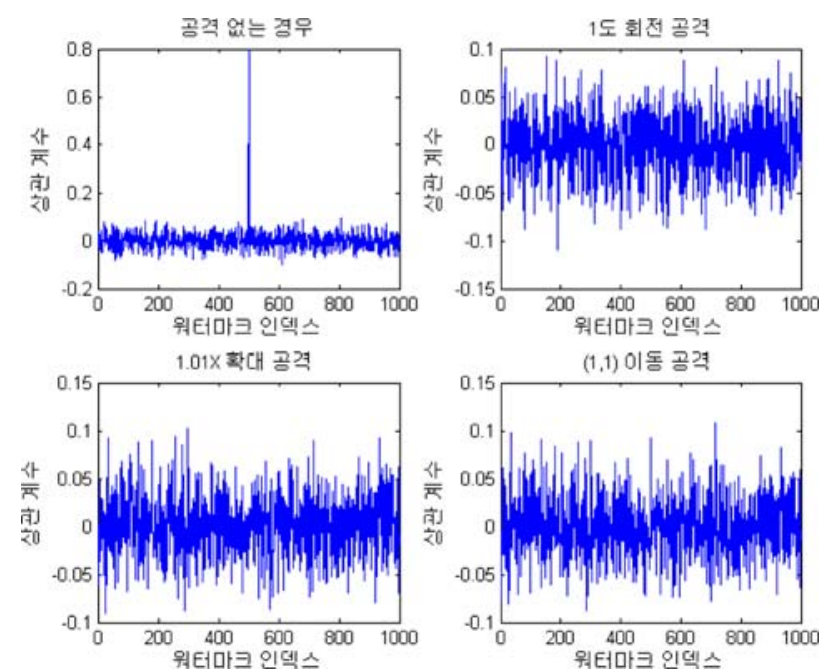

(그림 7) Gou와 Wu 알고리즘의 기하학적 공격에 대한 결과
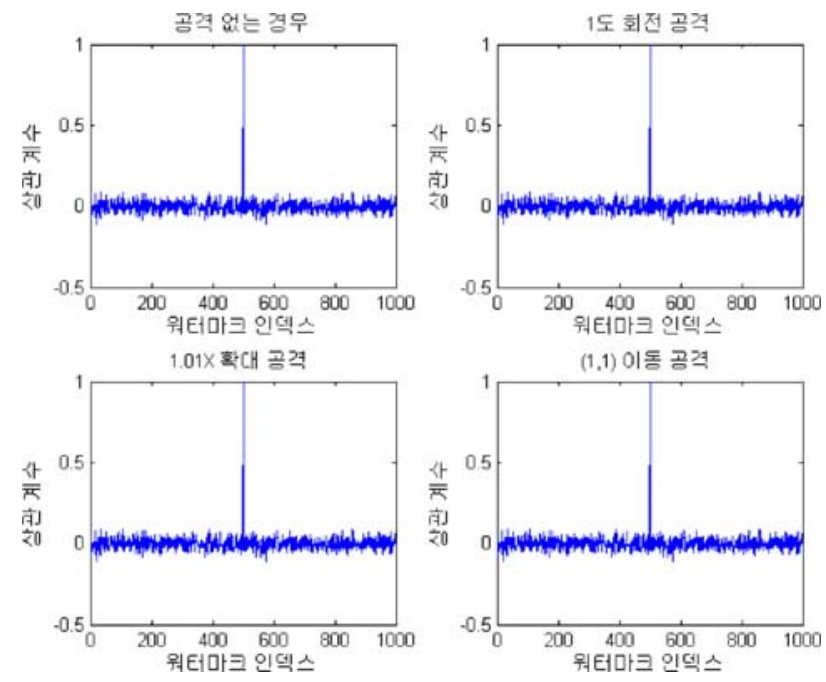

(그림 8) 제안한 워터마킹 방법의 기하학적 공격에 대한 결과

\section{2 프린트-스캔에 대한 실험}

오프라인 콘텐츠의 워터마킹을 위해 프린트-스캔에 대한 강인성은 필수적이다. 본 실험에서 9 개의 다른 선 이미지를 대상으로 $\mathrm{Gou}$ 와 $\mathrm{Wu}$ 의 워터마킹 알고리즘과 제안한 워터마 킹 알고리즘의 프린트-스캔에 대한 강인성을 비교하였다. 사용한 프린터는 HP Color Laserjet 4650이고 스캐너는 EPSON PERFECTION 2400 PHOTO이다. 먼저 프린터-스 캔을 수행하기 전에 워터마크된 선 이미지를 파일로 저장하 는 과정에서 좌표값 절삭으로 인한 선정보 훼손이 발생한 다. (그림 9)와 (그림 10)은 Car.tif 파일에 대해 실험한 결과 이다. 워터마크된 선 이미지를 파일로 저장한 경우와 추가 적으로 프린트-스캔 과정을 거친 이후 $Z$ 통계치를 비교하였 다. 결과에서 볼 수 있듯이 $\mathrm{Gou}$ 와 $\mathrm{Wu}$ 의 알고리즘의 경우 

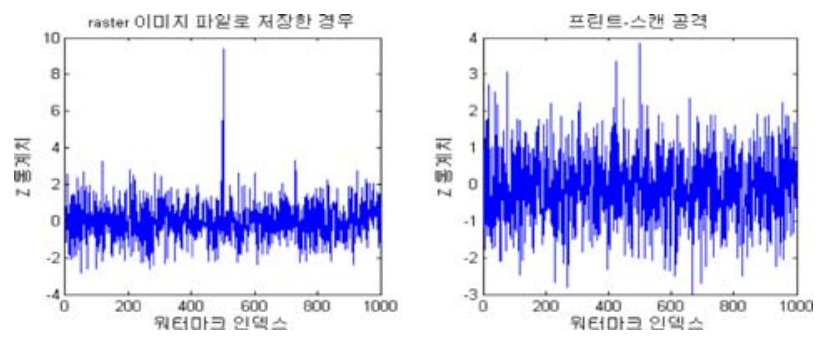

(그림 9) Gou와 Wu의 알고리즘의 프린트-스캔 공격에 대한 검 출 결과
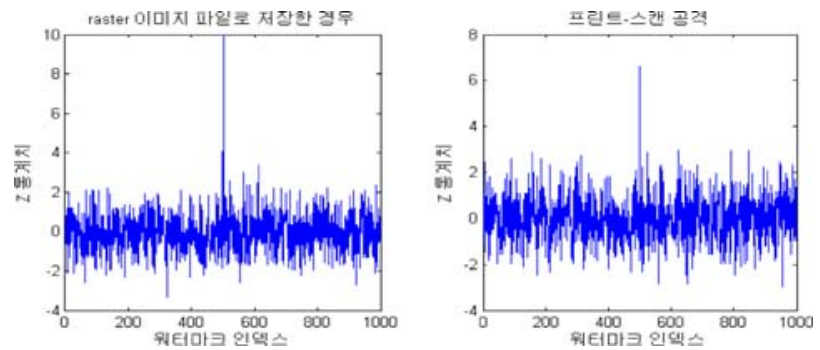

(그림 10) 제안한 알고리즘의 프린트-스캔 공격에 대한 검출 결과

통계치가 제안한 알고리즘의 통계치보다 낮다. 더욱이 프린 트-스캔 과정 이후에 통계치가 급격하게 낮아져서 워터마크 검출이 어렵다. 그러나 제안한 알고리즘에서는 프린트-스캔 이후에도 우수한 검출 결과를 보인다.

동일한 실험을 다른 이미지에 대해 동일하게 수행하였고, <표 3>에 그 결과를 정리하였다. 여기서 디지털화는 워터마 크된 선 이미지를 파일로 변환하는 과정을 의미하고, 디지 털화와 프린트-스캔 과정을 거친 이후의 이미지에 대하여 최대 $\mathrm{Z}$ 검출 통계치와 $\mathrm{HD}$ 분석 결과를 정리하였다.

워터마크된 선 이미지를 파일로 저장하는 경우, 기존 $\mathrm{Gou}$ 와 $\mathrm{Wu}$ 의 알고리즘 보다 제안한 워터마킹 알고리즘이 $28.4 \%$ 정도 향상된 검출율을 나타내었고, 프린트-스캔 과 정을 거친 이후에는 기존 알고리즘보다 $35.4 \%$ 정도의 검출 율 우수성을 보인다. 곡선의 왜곡을 나타내는 $\mathrm{HD}$ 의 경우도 기존 워터마킹 알고리즘보다 $4.0 \%$ 정도 개선된 결과를 나 타낸다.

〈표 3〉 워터마크 Z 검출 통계치와 HD 비교 결과

\begin{tabular}{|c|c|c|c|c|c|c|}
\hline \multirow{2}{*}{ 선 이미지 } & \multicolumn{2}{|c|}{$\mathrm{Gou}$ 와 $\mathrm{Wu}$ 의 알고리즘 } & \multicolumn{3}{|c|}{ 제안한 알고리즘 } \\
\cline { 2 - 7 } & 디지털화 & $\begin{array}{c}\text { 프린트 } \\
\text {-스캔 }\end{array}$ & $\mathrm{HD}$ & 디지털화 & $\begin{array}{c}\text { 프린트 } \\
\text {-스캔 }\end{array}$ & $\mathrm{HD}$ \\
\hline \hline Apple.tif & 8.51 & 6.06 & 4.0 & 9.02 & 8.74 & 4.0 \\
\hline Mountain.tif & 11.24 & 4.70 & 4.0 & 11.32 & 7.46 & 4.0 \\
\hline Car.tif & 9.41 & 3.85 & 5.2 & 9.98 & 6.60 & 4.0 \\
\hline Map.tif & 9.26 & 3.05 & 4.0 & 11.18 & 6.14 & 4.0 \\
\hline Leaf.tif & 8.70 & 4.08 & 4.5 & 11.40 & 5.42 & 4.0 \\
\hline Curve.tif & 3.32 & 3.25 & 4.0 & 6.48 & 3.39 & 4.0 \\
\hline Topo1.tif & 9.94 & 5.94 & 4.5 & 13.45 & 8.81 & 6.0 \\
\hline Topo2.tif & 12.21 & 3.09 & 6.0 & 18.99 & 3.17 & 6.0 \\
\hline Duck.tif & 9.39 & 6.03 & 6.0 & 13.45 & 12.26 & 4.5 \\
\hline
\end{tabular}

\section{5. 결론 및 향후 연구 과제}

산업 발달이 가속화되면서 다양한 콘텐츠들이 디지털화 되고 있고, 다양한 직선과 곡선으로 이루어져있는 네비게이 션 시스템이나 GIS의 디지털 지도에서 만화, 미술 작품에 이르기까지 다양한 콘텐츠가 디지털화 되어짐에 따라서 저 작권 침해의 위험에 노출되어 있다. 이들 콘텐츠는 기존 디 지털 워터마킹 기술에 사용한 데이터와 구조적으로 다르다.

본 논문에서는 선 이미지에 대해 $\mathrm{B}$-스프라인 곡선 모델 링을 수행하고, 메시-스펙트럼 분석을 통하여 주파수 영역 으로 표현하여, 워터마크를 삽입 및 검출하는 강인한 선 워 터마킹 알고리즘을 제안하였다. 제안한 선 워터마킹이 대표 적인 $\mathrm{Gou}$ 와 $\mathrm{Wu}$ 의 알고리즘에 비하여 파일 저장에 대해서 $28.4 \%$, 프린트-스캔에 대하여 워터마크 검출율에선 $35.4 \%$ 앞서면서도 곡선 왜곡은 $4.0 \%$ 덜 된다는 것을 실험 결과를 통해 확인하였다. 이는 프린트-스캔 과정에서 발생하는 공 격이 주로 고주파 영역에서 발생하고 저주파 영역은 선의 왜곡에 영향을 많이 미친다는 데에 착안하여 워터마크를 중 간 주파수 영역에 삽입한 결과이다.

제안한 워터마킹 알고리즘은 온라인 콘텐츠에 대해서 적 용할 수 있을 뿐만아니라, 선으로 이루어진 지도, 만화나 오 프라인 보안 제품 저작권 보호에 걸쳐 활용될 수 있다. 향 후 연구 방향은 현 알고리즘의 검출 결과의 향상과 실용화 에 제기되는 문제를 해결하는 것이다. 이를 위해 다양한 곡 선에 적합한 동기화 알고리즘을 적용해 볼 것이다. 또한 $1200 \mathrm{dpi}$ 이상의 고해상도를 지원하는 고급 프린터나 디지털 인쇄기 또는 오프셋 인쇄기를 이용한 고해상도 이미지에 대 한 프린트-스캔 실험을 할 것이다. 마지막으로 제안한 알고 리즘이 1-픽셀 곡선에 적용되기 때문에 다양한 픽셀 넓이의 선을 재현하지 못하는 문제점을 가지고 있다. 실용화를 위 하여 이들을 해결하는 연구를 하도록 하겠다.

\section{참 고 문 헌}

[1] V. Solachidis and I. Pitas, "Watermarking Polygonal Lines Using Fourier Descriptors," IEEE Computer Graphics and Applications, Vol.24, No.3, 1998.

[2] H. Gou and Min Wu., "Data Hiding in Curves With Application to Fingerprinting Maps," IEEE Trans. on Signal Processing, Vol.53, No.10, pp.3988-4004, 2005.

[3] R. Ohbuchi, H. Ueda and S. Endoh, "Watermarking 2D Vector Maps in the Mesh-Spectral Domain," Shape Modeling International, Vol.2003, pp.216-225, 2003.

[4] A. K. Jain, Fundamentals of Digital Imae Processing, Englewood Cliffs, NJ: Prentice Hall, 1989.

[5] K. Solanki, U. Madhow, B. S. Manjunath, S. Chandrasekaran and I. El-Khalil, "Print and Scan Resilient Data Hiding in Images," IEEE Trans. on Information Forensics and Security, Vol.1, No.4, 2006. 
[6] F. Mokhtarian and A. K. Mackworth, "A Theory of Multiscale, Curvature-Based Shape Representation for Planar Curves," IEEE Trans. on Pattern Analysis and Machine Intelligence, Vol.14, No.8, 1992.

[7] H. D. Brunk, An Introduction to Mathematical Statistics, Boston, MA: Ginn, 1960

[8] E. Belogay, C. Cabrelli, U. Molter, and R. Shonkwiler, "Calculating the Hausdorff Distance Between Curves," Information Processing Letter, Vol.64, No.1, pp.17-22, 1997.

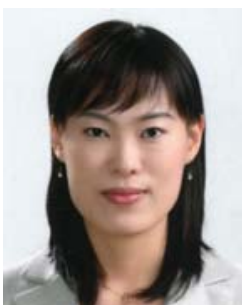

\section{김 지 영}

e-mail : jykim@mmc.kaist.ac.kr

2002년 한동대학교 전산전자공학부 전산학 전공 (학사)

2001년 2003년 (주)세아정보시스템 연구원

2003년 2005년 ProDVD Corp. 연구원

2006년 현 재 한국과학기술원 전자전산학과 전산학전공 석사과정

관심분야 : 디지털워터마킹, 콘텐츠보안, 미디어포렌식 등

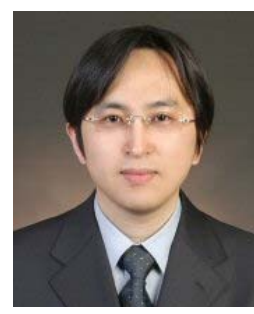

\section{이 해 연}

e-mail : haeyeoun.lee@kumoh.ac.kr 1997년 성균관대학교 정보공학과 (학사) 1999년 한국과학기술원 전산학과 (공학석사) 2006년 한국과학기술원 전자전산학과 전산학전공 (공학박사)

2001년 2006년 (주)쎄트렉아이 선임연구원 2006년 2007년 코넬대학교 박사후연구원 2008년 현 재 국립금오공과대학교 컴퓨터공학부 교수 관심분야 : 멀티미디어, 영상처리, 콘텐츠보안, 디지털워터마킹 등

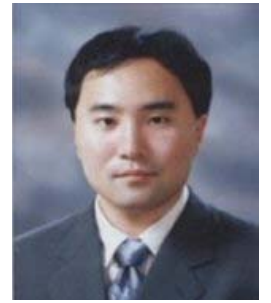

\section{임 동 혁}

e-mail : iammoni@mmc.kaist.ac.kr 2001년 연세대학교 컴퓨터공학과 (학사) 2001 2003년 (주버추얼텍 연구원

2006년 한국과학기술원 전자전산학과 전산학전공 (공학석사)

2006년 현 재 한국과학기술원 전자전산학과 전산학전공 박사과정

관심분야 : 디지털워터마킹, 디지털핑거프린팅, 미디어포렌식 등

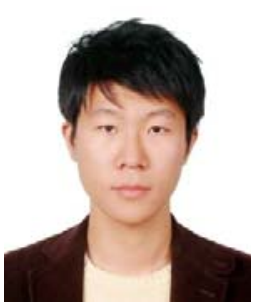

류 승 진

e-mail : sjryu@mmc.kaist.ac.kr

2007년 서울시립대학교 컴퓨터과학부 (학사) 2007년 현 재 한국과학기술원 전자전산학과 전산학전공 석박사통합과정

관심분야 : 디지털워터마킹, 미디어포렌식 등

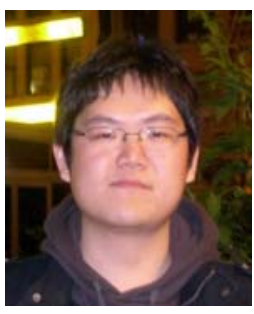

최 정 호

e-mail : jhchoi@mmc.kaist.ac.kr

2003년 한국과학기술원 전자전산학과 전산학전공 (학사)

2007년 현 재 한국과학기술원 전자전산학과 전산학전공 석사과정

관심분야 : 디지털워터마킹, 미디어포렌식 등

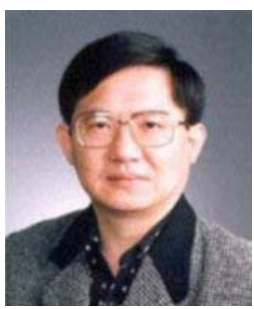

\section{이 흥 규}

e-mail : hklee@mmc.kaist.ac.kr 1978년 서울대학교 전자공학과 (학사) 1981년 한국과학기술원 전산학과 (공학석사) 1984년 한국과학기술원 전산학과 (공학박사) 1984년 1986년 Univ. of Michigan 연구원 1986년 현 재 한국과학기술원 전자전산학과 교수

1999년 2008년 한국과학재단지정 첨단정보기술연구센터 부소장 2006년 현 재 융합형보안기술연구센터 소장 관심분야 : 정보은닉, 미디어 포렌식, 스테가노그라피 